\title{
Impact of UV irradiation at full scale on bacterial communities in drinking water
}

Kristjan Pullerits ${ }^{1,2}$, Jon Ahlinder ${ }^{3}$, Linda Holmer ${ }^{4}$, Emelie Salomonsson ${ }^{3}$, Caroline Öhrman (iD) ${ }^{3}$, Karin Jacobsson (iD ${ }^{5,7}$, Rikard Dryselius ${ }^{5,8}$, Mats Forsman ${ }^{3}$, Catherine J. Paul (iD ${ }^{1,6 \bowtie}$ and Peter Rådström ${ }^{1}$

Water in a full-scale drinking water treatment plant was irradiated with ultraviolet (UV) doses of 250,400 , and $600 \mathrm{~J} / \mathrm{m}^{2}$, and the effect on bacterial communities investigated using 16s rRNA gene amplicon sequencing, heterotrophic plate counts (HPCs), coliform, and Escherichia coli counts. The bacteria in the irradiated water were also analyzed following storage for 6 days at $7{ }^{\circ} \mathrm{C}$, to approximate the conditions in the distribution system. The $\log _{10}$ reduction of HPCs at $400 \mathrm{~J} / \mathrm{m}^{2}$ was $0.43 \pm 0.12$. Phylogenetic examination, including DESeq2 analysis, showed that Actinobacteria was more resistant to UV irradiation, whereas Bacteroidetes was sensitive to UV. Phylum Proteobacteria contained monophyletic groups that were either sensitive or resistant to UV exposure. The amplicon sequence variants (ASVs) resistant to UV irradiation had a greater average GC content than the ASVs sensitive to UV, at $55 \% \pm 1.7(n=19)$ and 49\% $\pm 2.5(n=16)$, respectively. Families Chitinophagaceae, Pelagibacteraceae, Holophagaceae, Methylophilaceae, and Cytophagaceae decreased linearly in relative abundance, with increasing UV dose $(P<0.05$, Pearson's correlation). When irradiated water was stored, Chitinophagaceae, Comamonadaceae, and Flavobacteriaceae families decreased in relative abundance, whereas ACK-M1, Mycobacteriaceae, and Nitrosomonadaceae were increasing in relative abundance. This suggests that the impact of UV irradiation cannot only be considered directly after application but that this treatment step likely continues to influence microbial dynamics throughout the distribution system.

npj Clean Water (2020)3:11; https://doi.org/10.1038/s41545-020-0057-7

\section{INTRODUCTION}

Ultraviolet (UV) irradiation is widely used as a disinfection method for drinking water treatment. The technique became increasingly popular in the 1990s when its ability to disinfect water containing Cryptosporidium and Giardia was recognized'. Unlike other disinfection methods such as chlorination or ozonation, UV irradiation requires no addition of chemicals and low-pressure UV produces insignificant amounts of disinfection byproducts ${ }^{1,2}$. Various bacteria have different UV susceptibility: a $4-\log _{10}$ reduction of a lab-grown environmental isolate of Mycobacterium avium requires a dose of $128 \mathrm{~J} / \mathrm{m}^{2}$ UV $254 \mathrm{~nm}^{3}$, whereas for the same reduction, cultivated environmental isolate of Escherichia coli requires a dose of $81 \mathrm{~J} / \mathrm{m}^{2} 4$. The dose required for disinfection can also be affected by suspended particles in the water, which can absorb and scatter UV light and affect UV efficiency ${ }^{5,6}$.

The disinfection mechanism resulting from exposure to UV is mainly damage to nucleic acids by irradiation ${ }^{7}$. Nucleotides absorb UV light with wavelengths of between 200 and $300 \mathrm{~nm}$ with a peak absorption between 260 and $265 \mathrm{~nm}^{8}$. The absorption of light triggers the formation of mutagenic DNA lesions, such as cyclobutane pyrimidine dimers and 6-4 photoproducts ${ }^{9}$. Both pyrimidines and purines can absorb UV light, although pyrimidines are considered to be more photoreactive ${ }^{10,11}$. When nucleotides are damaged by UV light, the DNA replication is blocked, resulting in cell inactivation ${ }^{12,13}$. Some microorganisms are able to repair UV damage either by photoreactivation or dark repair $^{9,14}$.
The impact of UV on target microorganisms has largely been studied using cultivation-based techniques of monocultures at laboratory scale ${ }^{1}$. At full scale, a biodosimetry test is used to calibrate the irradiation dose for UV reactors by spiking a known concentration of a specific cultured microorganism and calculating the log-reduction. This is compared with results from a calibrated laboratory UV reactor to calculate the final UV dose of the full-scale UV reactor at a specific UV transmission and flow ${ }^{15}$. The validity of these tests to assess disinfection of drinking water, however, is debatable, as the majority of microorganisms in drinking water cannot currently be cultivated $^{16}$, bacteria in drinking water are diverse, and bacteria in the environment have an increased UV resistance compared with laboratory-cultivated strains ${ }^{1}$. Exposure to UV can also cause some bacteria to enter a viable but nonculturable state as a response to environmental stress ${ }^{17,18}$.

Molecular DNA-based methods analyze the microbial community without the need for cultivation and, as UV irradiation causes DNA lesions and reduces the number of amplifiable target templates in the PCR reaction ${ }^{13,19}$, amplicon-based methods can describe which types of bacteria and genes are affected by UV $\mathrm{U}^{20-22}$. Microbial inactivation of Pseudomonas aeruginosa and Enterococcus faecium by UV was assessed by cultivation and quantitative PCR $(\mathrm{qPCR})^{19}$ and impact of UV on adenovirus concentrations were measured by cell culture infectivity and long-range PCR with subsequent $\mathrm{GPCR}^{23}$. The impact of UV irradiation on the number of bacteria in drinking water has been quantified with 16s rRNA gene amplification $^{24}$.

\footnotetext{
${ }^{1}$ Applied Microbiology, Department of Chemistry, Lund University, P.O. Box 124, SE-221 00 Lund, Sweden. ${ }^{2}$ Sweden Water Research AB, Ideon Science Park, Scheelevägen 15, SE22370 Lund, Sweden. ${ }^{3} \mathrm{FOI}$, Swedish Defence Research Agency, Cementvägen 20, SE-906 21 Umeå, Sweden. ${ }^{4}$ Norrvatten, Box 2093 , SE-169 02 Solna, Sweden. ${ }^{5}$ Swedish Food Agency, Box 622, SE-751 26 Uppsala, Sweden. ${ }^{6}$ Water Resources Engineering, Department of Building and Environmental Technology, Lund University, P.O. Box 118, SE-221 00 Uppsala, Sweden. ${ }^{7}$ Present address: Swedish University of Agricultural Sciences, Box 7036, SE-750 07 Uppsala, Sweden. ${ }^{8}$ Present address: Health Agency of Sweden, SE-171 82 Solna, Sweden ${ }^{凶}$ email: catherine.paul@tvrl.Ith.se
} 
Although the value of UV irradiation for reduction of microbial pathogens in drinking water is not disputed, it is not known how UV irradiation impacts other bacteria that are undesirable. Some bacteria can cause water quality issues, by producing unpleasant odors and tastes ${ }^{25}$, or exacerbate corrosion of infrastructure ${ }^{26}$. Descriptions of the bacterial community in water using $16 \mathrm{~s}$ rRNA gene amplicon sequencing have described changes in drinking water during distribution ${ }^{27}$; however, few studies exist, examining the impact of UV exposure on the bacterial community in drinking water. An initial study using 16s rRNA gene amplicon sequencing conducted by Nocker et al. ${ }^{21}$ showed how some phyla of bacteria were affected by a single dose of UV in a full-scale drinking water treatment plant. The approach of using 16S rRNA gene amplicon sequencing has been used to observe changes in the bacterial community for UV wastewater disinfection ${ }^{22}$ and UV irradiation of marine water ${ }^{28}$.

The current study is a detailed examination of the impact of three different UV irradiation doses $\left(250,400\right.$, and $\left.600 \mathrm{~J} / \mathrm{m}^{2}\right)$ in drinking water at full scale. The contents and diversity of the bacterial community was assessed using 16S rRNA gene amplicon sequencing. The results of this molecular analysis were compared with traditional cultivation-based methods determining heterotrophic plate counts (HPCs), coliforms, and E. coli. To understand how changes might occur during distribution of water irradiated with UV, bacterial communities of irradiated water, stored at temperatures simulating those of a distribution system, were also investigated.

\section{RESULTS}

Effect of UV irradiation on bacterial community structure

The bacterial community in water irradiated with different UV doses $\left(250,400\right.$, and $\left.600 \mathrm{~J} / \mathrm{m}^{2}\right)$ and following 6 days water storage at $7^{\circ} \mathrm{C}$ was investigated using $16 \mathrm{~S}$ rRNA gene amplicon sequencing (Fig. 1). Canonical correspondance analysis (CCA) of the relative abundances of amplicon sequence variants (ASVs), which takes into account the parameters of UV dose and storage, showed increasingly dissimilar bacterial communities with higher UV dose $(P<0.001$, CCA followed by analysis of variance (ANOVA)). This was also observed with ordination analysis using the Bray-Curtis distance between samples (Supplementary Fig. 1). Although storage of the water affected the community composition of the UV-irradiated samples (Supplementary Fig. 2A,

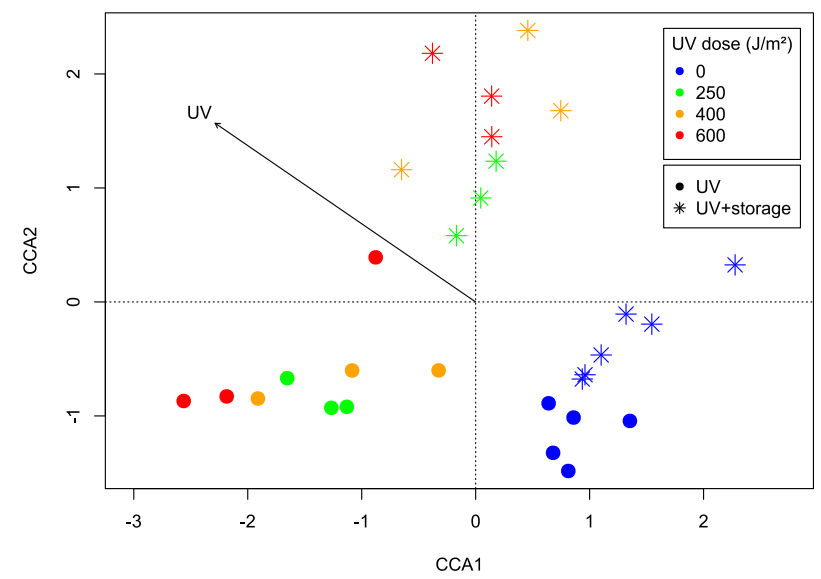

Fig. 1 Canonical correspondence analysis (CCA) of bacterial communities and UV dose. UV dose is used as a numeric variable and sample type as a factor. Bacterial communities were analyzed from water exposed to UV $\left(0,250,400\right.$, and $600 \mathrm{~J} / \mathrm{m}^{2}$; blue, green, orange, and red circles, respectively) or after storage (6 day storage at $7{ }^{\circ} \mathrm{C}$, stars); $n=5$ for UV dose of $0 \mathrm{~J} / \mathrm{m}^{2}$ and $n=6$ for storage not exposed to UV; $n=3$ for all UV doses $>0$ and sample type.
$P<0.001, R^{2}=0.62$, Analysis of Dissimilarities (ADONIS), storage had no impact on the bacterial community that had not been irradiated by UV according to Bray-Curtis analysis (Supplementary Fig. 2B, $P=0.36, R^{2}=0.10$, ADONIS).

To further investigate how irradiation shaped the bacterial community structures, alpha diversity was assessed by comparing evenness (Pielou's measure), species richness (number of observed ASVs), and diversity (Shannon index) (Supplementary Fig. 3). When all water samples exposed to UV irradiation (250, 400 , and $600 \mathrm{~J} / \mathrm{m}^{2}$ ) were grouped, the evenness of the community increased compared with the non-irradiated water from $0.49 \pm$ 0.016 to $0.54 \pm 0.025$ ( $P<0.001$, one-way ANOVA). Species richness in water samples ranged from 109 to 140 , but no changes in species richness were observed by UV irradiation $(P>0.05$, oneway ANOVA). Changes in Shannon diversity reflected those in evenness, with UV exposure resulting in increased Shannon diversity in the bacterial communities, from $2.33 \pm 0.094$ for nonirradiated communities to $2.61 \pm 0.12$ when all water samples exposed to UV were grouped for analysis $(P<0.001$, one-way ANOVA).

The effects of UV irradiation were observed as changes in the relative abundance of specific bacterial taxa as the UV dose increased (Fig. 2). Following agglomeration of ASVs into phylum level, Bacteroidetes decreased in relative abundance $(P<0.05$, Pearson's correlation), whereas Actinobacteria increased in relative abundance $(P<0.05$, Pearson's correlation). Five families showed linear decreases in relative abundance $(P<0.05$, Pearson's correlation), including Pelagibacteraceae $(R=-0.74)$, Chitinophagaceae $(R=-0.96)$, Holophagaceae $(R=-0.71)$, Methylophilaceae $(R=$ $-0.61)$, and Cytophagaceae $(R=-0.8)$. Within the Chitinophagaceae family, the Sediminibacterium genus showed a strong linear decrease in relative abundance $(R=-0.97, P<0.05$, Pearson's correlation; Supplementary Fig. 10).

Phylogenetic relationships of bacteria impacted by UV

ASVs from bacteria affected by UV irradiation were identified by differential abundance analysis using DESeq2 where negative and positive $\log _{2}$ fold changes were defined as sensitive- and resistant to UV, respectively. Thirty-five out of 164 ASVs with a significant change in differential abundance $\left(P_{\text {adjusted }}<0.05\right)$ were identified (Supplementary Figs 4 and 5). Specific clades were identified by their sensitivity to UV (Fig. 3), phylum Bacteroidetes was sensitive to UV, with ASVs identified as Sediminibacterium, Sphingobacteriaceae, and Cytophagaceae having a negative $\log _{2}$ fold change. Phylum Actinobacteria was resistant to UV with ASVs classified as families $A C K-M 1$ and $C 111$ with a positive $\log _{2}$ fold change. The Proteobacteria phylum included ASVs that were both sensitive and resistant to UV: ASVs classified as Pelagibacteraceae (order Ricketsiales, Alphaproteobacteria), Methylophilaceae (Betaproteobacteria), and Limnohabitans (Betaproteobacteria) showed a negative $\log _{2}$ fold change, whereas others including Rhodospirillaceae (Alphaproteobacteria), Ralstonia (Betaproteobacteria), Polynucleobacter (Betaproteobacteria), and Rhodoferax (Betaproteobacetria) demonstrated positive $\log _{2}$ fold changes. Phylogeny was determined to be a cause for UV sensitivity when the community sensitive to UV, which consisted of 16 ASVs showed a difference in composition compared with all identified ASVs in the samples at phylum level ( $P=0.020$, Fisher's exact test). The GC content of the $16 \mathrm{~S}$ rRNA gene region of ASVs identified by DESeq2 analysis was calculated (Supplementary Table 2) where ASVs with positive $\log _{2}$ fold change $(n=19)$ had a significantly greater average GC content compared with ASVs with negative $\log _{2}$ fold change $(n=16)$, $55 \% \pm 1.7$ and $49 \% \pm 2.5$, respectively $(P<0.001$, one-way ANOVA). 

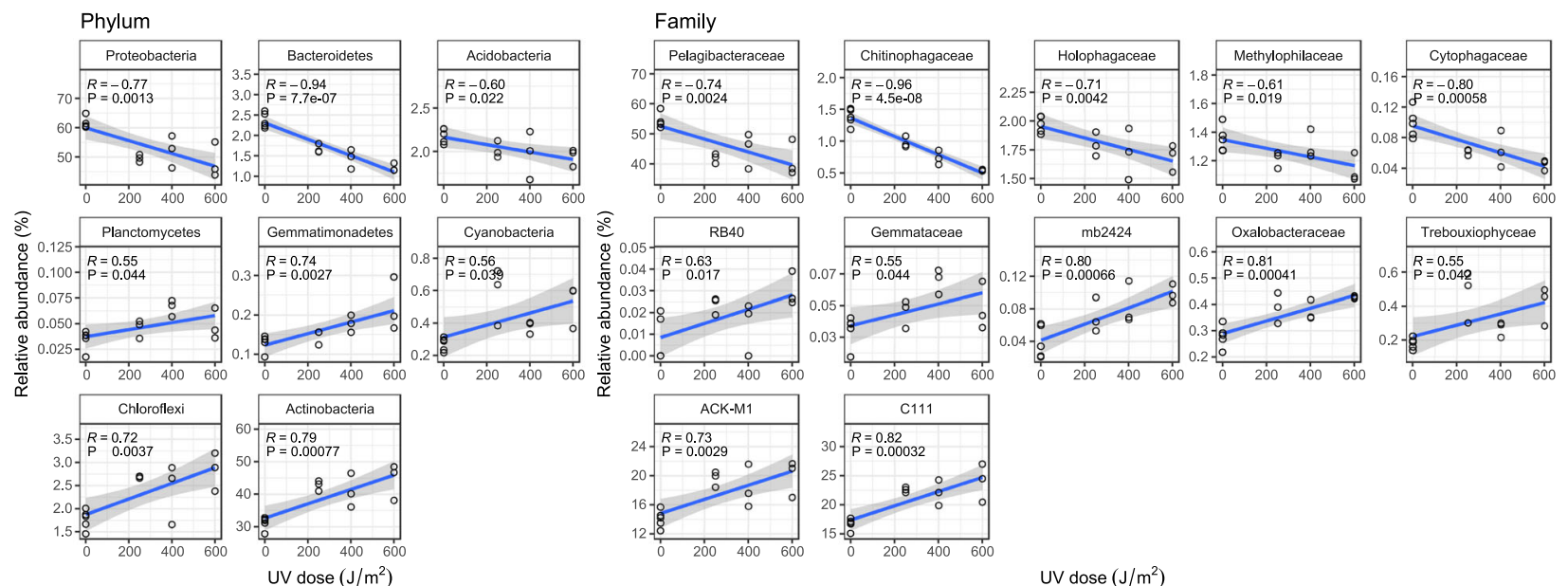

Fig. 2 Impact of UV dose at phylum and family level. Linear regressions (blue line) of the relative taxonomic abundance again UV dose are shown, with the gray transparent area showing the $95 \%$ confidence interval. Reads were agglomerated to phylum or family level. Only phyla and families with significant regression correlation $(P<0.05$, Pearson's correlation) are shown; see Supplementary Figs $6-10$ for full data set at all taxonomic ranks. Taxa are ordered with the greatest negative slope correlation in top left with subsequent increase. $n=3$ for each UVirradiated sample, $n=5$ for the non-irradiated samples.

Impact of water storage on bacterial communities exposed to UV irradiation

As water exposed by UV irradiation is often distributed to the consumer over a period of days and at low temperatures, changes that could occur in the bacterial community following irradiation and distribution were assessed (Fig. 1). To replicate these conditions, water samples were stored for 6 days at $7{ }^{\circ} \mathrm{C}$ following UV exposure. The alpha diversity measure evenness recovered after storage to similar levels as before UV irradiation when the UV-irradiated and -stored samples were grouped together and compared with the non-irradiated samples, $0.49 \pm 0.026$ (mean \pm SD) and $0.48 \pm 0.034$, respectively (Supplementary Fig. 3). The storage did not affect the species richness $(P>0.05$, one-way ANOVA). As with evenness, the Shannon diversity also recovered after storage for the grouped irradiated and stored samples to the same levels as the non-irradiated samples, Shannon index $2.36 \pm$ 0.14 and $2.29 \pm 0.16$, respectively.

To assess which bacteria were able to repair the UV damage or regrow faster than other members in the community, the relative abundance of ASVs representing bacterial taxa in the UVirradiated water were compared before and after storage (Fig. 4). Following UV irradiation, the Pelagibacteraceae family comprised $37-50 \%$ of the community (Fig. 2) but after storage this increased to $46-59 \%$ (Fig. $4, P<0.05$, one-way ANOVA). The families Flavobacteriaceae, Trebouxiophyceae, C111, and Hyphomicrobiaceae were not initially affected or increased in relative abundance by UV irradiation (Fig. 2 and Supplementary Fig. 9), but decreased in relative abundance after storage (Fig. $4, P<0.05$, one-way ANOVA). A relative decrease in the Trebouxiophyceae family and changes in relative abundance for 6 (out of 34) additional families $(P<0.05$, one-way ANOVA) were observed when the water that had not been UV-irradiated was stored (Supplementary Fig. 16).

To assess the impact of UV exposure on the bacterial community in distributed water, the relative abundance of bacterial taxa in stored water that had, or had not been irradiated with UV were compared (Fig. 5). Five families of bacteria decreased in relative abundance when water exposed to UV was stored, including Flavobacteriaceae, Chitinophagaceae, Cytophagaceae, Comamonadaceae, and Sphingobacteriaceae (one-way ANOVA, $P<0.05$ ), and 11 families increased in relative abundance following UV exposure and storage, including ACK-M1, Oxalobacteraceae, Nitrosomonadaceae, Rhodospirillaceae, mb2424, Sinobacteraceae, LD19 Trebouxiphyceae,
Gemmatimonadaceae, Mycobacteriaceae, and Acetobacteraceae $(P<$ 0.05 , one-way ANOVA).

Impact of UV on conventional microbial indicators

HPCs were assessed for water irradiated with 250, 400, and $600 \mathrm{~J} /$ $\mathrm{m}^{2}$, and after storage. HPCs in the UV-exposed water decreased to an average of $1.2 \pm 0.83 \mathrm{CFU} / \mathrm{mL}$ from $4.5 \pm 1.4 \mathrm{CFU} / \mathrm{mL}$ (Fig. $6, P<$ 0.001 , one-way ANOVA). There was no significant change in HPCs between the three different doses $(P>0.05$, one-way ANOVA, followed by a Tukey's test): $\log _{10}$ reductions in HPCs were $0.53 \pm$ 0.12 and $0.43 \pm 0.12$ for $250 \mathrm{~J} / \mathrm{m}^{2}$ and $400 \mathrm{~J} / \mathrm{m}^{2}$, respectively. Although the number of heterotrophic bacteria increased during storage in the non-irradiated samples, from $4.5 \pm 1.4$ to $8.7 \pm$ 6.2 CFU $/ \mathrm{mL}$, this was not statistically significant $(P>0.05$, one-way ANOVA). HPCs in water that had been UV-irradiated did not change during storage, regardless of dose $(P>0.05$, one-way ANOVA, followed by a Tukey's test). No differences in fast growing HPCs after 3 days were seen for any of the samples $(P>0.05$, oneway ANOVA, followed by a Tukey's test; Supplementary Fig. 17). To assess coliform counts, $60 \mathrm{~L}$ of water was concentrated using dead-end hollow-fiber ultrafiltration ${ }^{29}$ following exposure of the water to 0,400 , and $600 \mathrm{~J} / \mathrm{m}^{2}$ ( $n=3$ for each dose). Coliforms $(1.7 \pm 0.57$ coliforms $/ 10 \mathrm{~L})$ and $E$. coli $(0.97 \pm 0.93 \mathrm{E}$. coli/ $10 \mathrm{~L})$ were detected in the concentrates of the untreated water but not in any sample of water exposed to UV (Supplementary Table 1).

\section{DISCUSSION}

As bacteria in drinking water are diverse and likely have different susceptibility to $\mathrm{UV}^{1}$, this study examined bacterial communities in water irradiated with different UV doses, using 16S rRNA gene amplicon sequencing. The impact of storage on the relative abundance of different taxa was also determined to describe how exposing water to UV irradiation could alter the microbiology of the distributed water. The community descriptions were compared with conventional methods using indicator bacteria to assess and compare how these approaches reflect the impact of UV irradiation on microbial water quality.

Examining the relationship between phylogeny and UV exposure revealed bacterial clades that were both sensitive and resistant to UV. Actinobacteria phylum was resistant, Bacteroidetes phylum showed sensitivity to UV, whereas some monophyletic groups in the Proteobacteria phylum showed sensitivity and others 


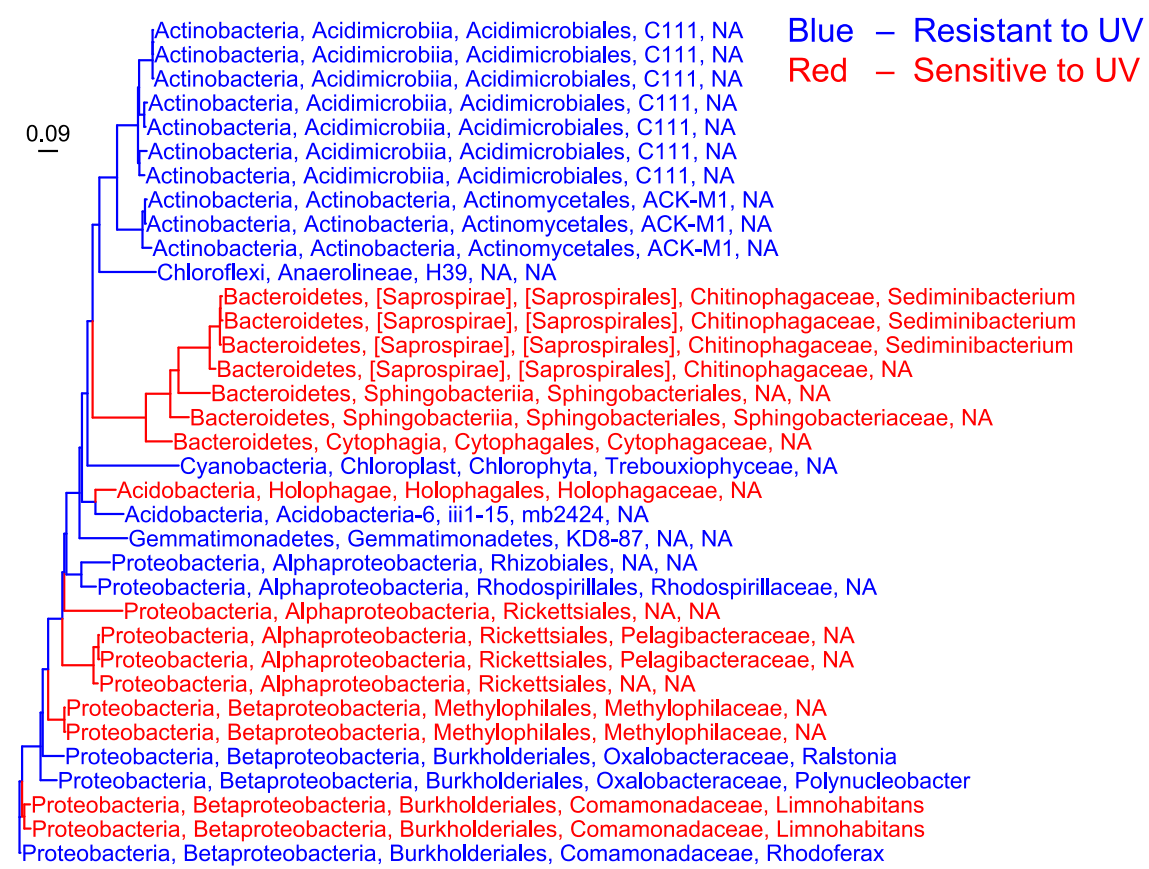

Fig. 3 Phylogenetic tree of ASVs identified as sensitive and resistant to UV. The inferred phylogenetic tree with branches colored by sensitivity and resistant to UV was created with ASVs recognized as having a signficant change with differential abundance analysis using DESeq2 $\left(P_{\text {adjusted }}<0.05\right)$. Samples not exposed to UV $(n=5)$ were compared to UV irradiated samples $(n=9)$, with the dose as a numeric parameter. A negative log2fold change was considered a UV-sensitive taxa (red) and positive log2fold change as a UV-resistant taxa (blue). The scale bar shows an estimate of the substitutions per nucleotide position. See Supplementary Fig. 4 and Supplementary Table 2 for output data from DESeq2. See Supplementary Fig. 5 depicting the ASVs classified as sensitive and resistant to UV among all identified ASVs.

resistance to UV (Fig. 3). Low and high GC content calculated from the different ASV DNA sequences correlated with how the taxa were categorized as sensitive or resistant to UV, respectively (Supplementary Table 2). It has been proposed that the high genomic GC content in Actinobacteria contributes to their UV resistance ${ }^{30}$, perhaps as $\Pi$ and TC nucleotide sites are more photoreactive $^{31}$. Reichenberger et al. ${ }^{32}$ proposed that phyla could be classified into GC-rich (Actinobacteria), GC-intermediate (Proteobacteria), and GC-poor (Bacteroidetes), linking UV sensitivity to a genomic, and thus heritable, trait. Nocker et al. ${ }^{21}$ showed resistance of Actinobacteria to UV in drinking water and suggested that the Proteobacteria phylum is sensitive to UV. In addition to GC content, Actinobacteria, Bacteroidetes, and Proteobacteria have distinct membrane structures that can result in these bacteria having different degrees of resistance to $U^{33}$. A study from McKinney and Pruden ${ }^{20}$ observed that two Gram-positive organisms (Staphylococcus aureus and E. faecium, both Firmicutes) were more resistant to UV irradiation than two Gram-negative bacteria (E. coli and P. aeruginosa, phylum Proteobacteria and Firmicutes, respectively), which could be due to the thicker peptidoglycan layer in Gram-positive organisms protecting the cells from UV damage. Actinobacteria are Gram-positive and have been isolated in environments exposed to strong solar UV radiation ${ }^{30,34}$. In addition, Actinobacteria are spore forming ${ }^{35}$ and this can also contribute to their resistance to $\mathrm{UV}^{36,37}$. In contrast the phyla Bacteroidetes are Gram-negative rods that do not form endospores $^{38}$ and this combination could be a reason for the sensitivity to UV demonstrated by the members of the Bacteroidetes phylum observed in the current study. Strains classified in the Bacteroidetes phylum are abundant in high-altitude lakes receiving strong UV radiation from the sun ${ }^{39}$, suggesting tolerance to UV exposure; however, the Bacteroidetes phylum is diverse and the members of the Bacteroidetes in this study may be UV-sensitive, as the source water used in the treatment plant in this study is from a low-altitude lake. Proteobacteria are Gram-negative and the division is the largest and most diverse among prokaryotes ${ }^{40}$. In this study within the Proteobacteria, the response to UV seemed largely related to GC content. In Alphaproteobacteria, the Rickettsiales order was sensitive to UV (low GC content, ranging from $\sim 30 \%$ to $40 \%{ }^{41}$ ), whereas the Rhodospirillaceae family (high GC content of $\sim 65 \%{ }^{41}$ ) was resistant to UV, and in Betaproteobacteria, the Methylophilaceae family showed sensitivity to UV (low GC content of $\sim 35-40 \%{ }^{42}$, whereas Ralstonia and Rhodoferax were resistant to UV (high GC content of $\sim 67 \%{ }^{43}$ and $\sim 60 \%{ }^{44}$, respectively). The exceptions were the sensitivity of Polynucleobacter, with a GC content of $\sim 45 \%{ }^{45}$ to UV, and that members of Limnohabitans (GC content of $59 \%{ }^{44}$ ) were both resistant and sensitive. These observations could be due, in part, to the few isolates of these bacteria that have been sequenced, to determine GC content, which may differ from those present in this study.

Depending on the time for drinking water to reach consumers, some bacteria in the water could repair UV damage ${ }^{46}$ received at the treatment plant. In this study, the evenness and diversity of the bacterial community were affected by UV, although both metrics indicated that the community rebounded following storage. This could largely be attributed to changes in the relative abundance of Pelagibacteraceae, which was highly abundant in the community. The relative abundance of this family recovered after UV exposure and storage (Fig. 4), possibly due to the ability of these bacteria to repair UV damage and/or by surviving the UV exposure, and then regrowing faster than the other surviving taxa. As Pelagibacteraceae, or the SAR11 clade, are abundant in drinking water $^{47}$ and marine water ${ }^{48,49}$; they may have acquired UV resistance to survive the UV exposure from the sun in their preferred niche and, with a large surface-to-volume ratio, efficient nutrient uptake in oligotrophic environments ${ }^{50}$ allows them to grow faster than other members of the bacterial community ${ }^{51}$.

The relative abundance of families Flavobacteriaceae, Trebouxiophyceae, C111, and Hyphomicrobiaceae was initially not affected or increased by UV irradiation (Supplementary Fig. 14) but during storage decreased in relative abundance (Fig. 4). The initial relative UV resistance of these taxa could be due to the 16S rRNA gene not 


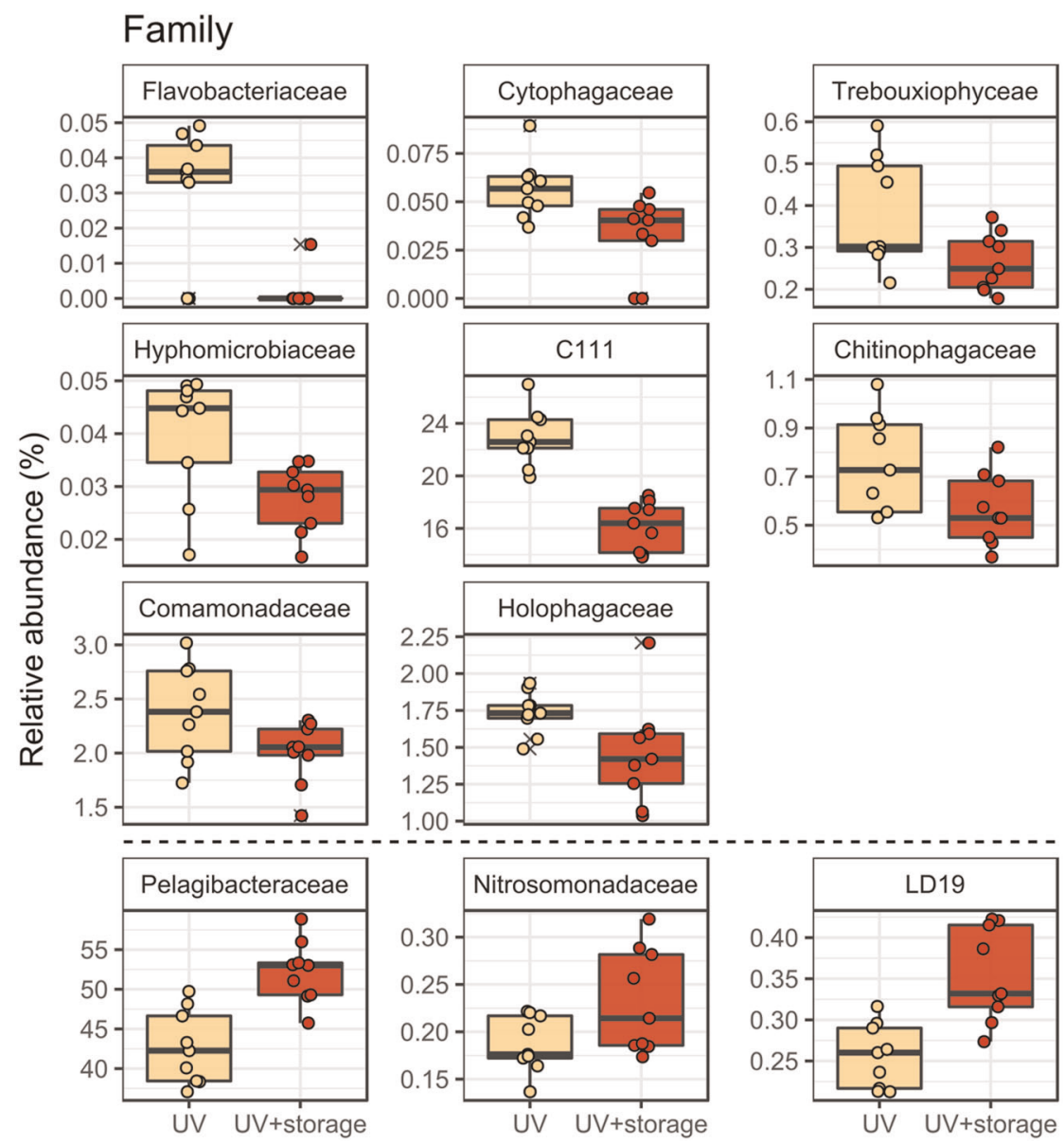

Fig. 4 Comparison of bacterial taxa at family level, in water samples exposed to UV, with and without storage. Relative abundance of bacterial taxa in water samples exposed to UV, and then stored for 6 days at $7^{\circ} \mathrm{C}$ (red), or not stored (gold), were compared. Only families with significant difference in relative abundance between groups $(P<0.05$, one-way ANOVA) are shown, see Supplementary Figs $11-15$ for full data set. Families are ordered with the most relative change in the top left with subsequent decrease. The boxes show the interquartile range, the line inside each box represents the median, whiskers show maximum and minimum values, and the crosses show outliers. $n=9$ for water samples exposed to UV and $n=9$ for water exposed to UV and incubated. Samples irradiated at different UV doses were grouped for this analysis.

receiving any DNA lesions, but damage by UV irradiation can also cause cell death via by, e.g., creating protein-DNA crosslinks ${ }^{52}$, which would not be detected with 16S rRNA gene amplicon sequencing. In addition, although valuable in many applications, the use of viability dyes (e.g., propidium monoazide (PMA) and propidium iodide $(\mathrm{PI})$ ) together with $\mathrm{qPCR}$ or flow cytometry (Supplementary Table 5) to assess UV disinfection is difficult, as UV irradiation damages DNA and not cell membranes.

UV irradiation is increasingly considered as a disinfection process for drinking water, and with specific observations of how the bacterial community would change during distribution from a treatment plant applying UV, it was also important to understand how this community compared with distributed water that had not been UV-irradiated water. After storage, some families, including Chitinophagaceae, Comamonadaceae, and Flavobacteriaceae decreased in relative abundance in water that had been UV-irradiated compared with untreated, stored water, whereas other families increased in relative abundance, including ACK-M1, Mycobacteriaceae, and Nitrosomonadaceae (Fig. 5). The ACK-M1 family is included in the Actinomycetales order and the presence of Actinomycetes has been associated with taste and odor problems, due to their production of odorants, including 2methylisoborneol (2-MIB) $)^{25}$. 2-MIB is an odorant that is difficult to remove with conventional water treatment processes; however, Chitinophagaceae bacterium, among other bacteria isolated from an activated carbon filter, are able to biodegrade $2-\mathrm{MIB}^{53}$. This suggests that UV treatment may both increase the abundance of bacteria associated with production of odorants and decrease those with the potential to biodegrade the problematic compounds. This may be a concern for drinking water treatment plants, as preventing taste and odor problems in drinking water is of great importance ${ }^{25}$.

In addition to aesthetic compounds, the presence of opportunistic pathogens such as Legionellae, Mycobacteria, and $P$. aeruginosa are a concern in distributed water and can also persist in biofilms ${ }^{54}$. In this study, family Mycobacteriaceae (classified as Mycobacterium; Supplementary Fig. 15) was detected in higher relative abundance in water after UV exposure and storage, than in untreated, stored water (Fig. 5). Shin et al. ${ }^{55}$ have described $M$. avium as more resistant to UV irradiation than other waterborne pathogens, and as this species has also shown resistance to other disinfection methods such as chlorine, monochloramine, chlorine dioxide, and ozone ${ }^{56}$, it could be of concern for drinking water producers.

Not much is known about how a UV installation will affect the biofilm in the drinking water distribution system (DWDS) in the long term ${ }^{57}$. The biofilm community in DWDS is complex and can differ depending on location and material ${ }^{58,59}$. The genus Nitrosomonas, included in the Nitrosomonadaceae family, which increased in relative abundance by UV irradiation and storage (Fig. 5), has been found in DWDS biofilms ${ }^{60,61}$. Comamonadaceae has been observed in DWDS biofilms ${ }^{62}$ and Flavobacterium, 


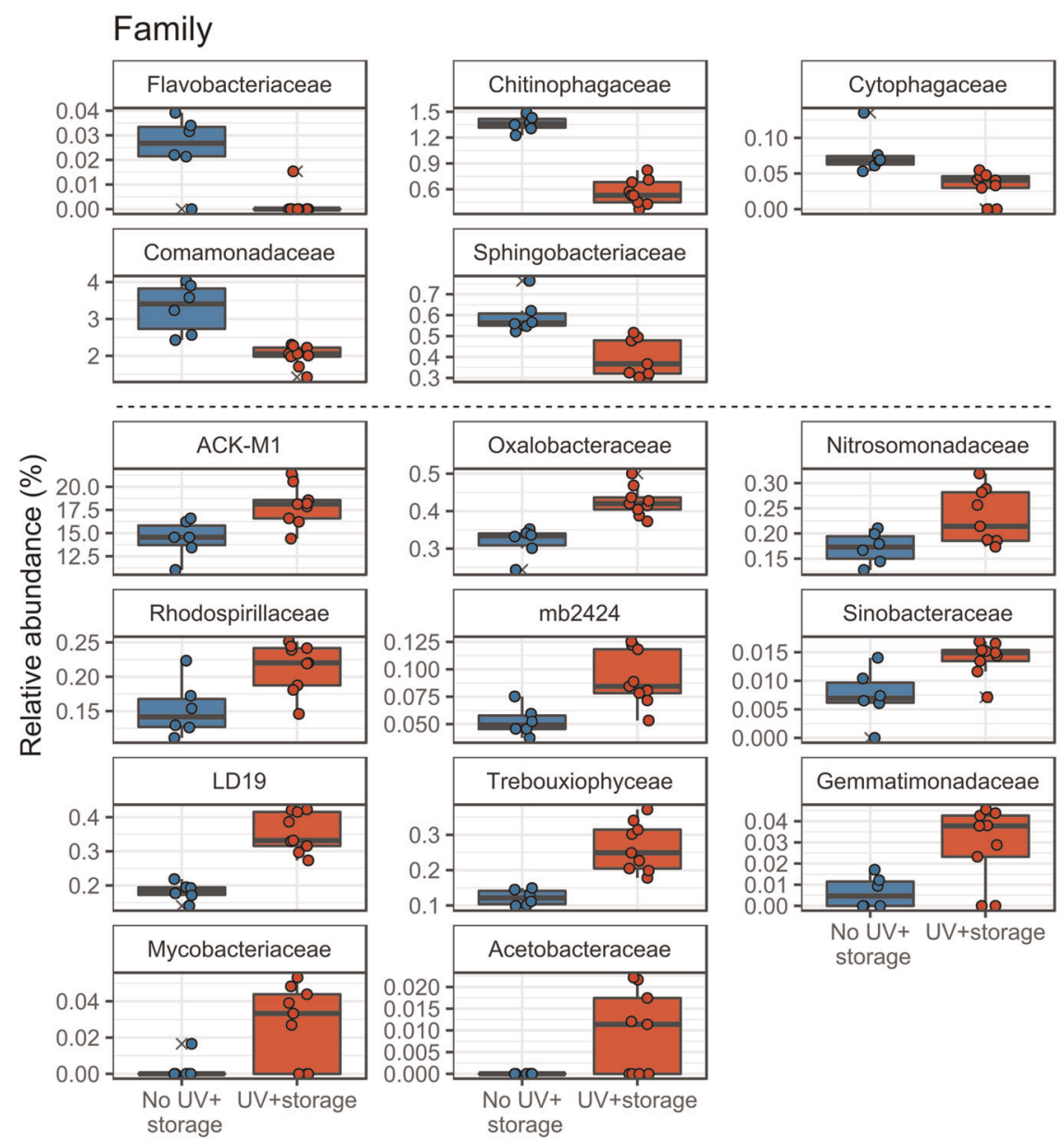

Fig. 5 Comparison of bacterial taxa at family level following storage of water. Relative abundance of bacterial taxa in water samples that were stored for 6 days at $7{ }^{\circ} \mathrm{C}$, and were either not exposed (blue) or exposed (red) to UV. Only families with significant difference in relative abundance between groups $(P<0.05$, one-way ANOVA) are shown; see Supplementary Figs $11-15$ for full data set. Families are ordered with the most relative change in the top left with subsequent decrease. The boxes show the interquartile range, the line inside each box represents the median, whiskers show maximum and minimum values, and the crosses show outliers. $n=6$ for no UV samples and $n=9$ for UV-irradiated samples. Samples irradiated at different UV doses were grouped for this analysis.

included in the Flavobacteriaceae family, has been observed in drinking water wells ${ }^{63}$, both decreasing in relative abundance by UV irradiation and storage in this study. If a treatment plant using UV disinfection selects for certain bacteria, this will inevitably shape the DWDS biofilm, which will affect the water quality in the end.

Despite the observation in this, and other studies that bacteria are affected differently by UV irradiation, biodosimetry tests are based on single target organisms. This makes it difficult to assess UV irradiation in full scale $21,24,64$. However, in this study families Chitinophagaceae, Pelagibacteraceae, Holophagaceae, Methylophilaceae, and Cytophagaceae showed sensitivity to UV in a linear correlation with dose (Fig. 2). These bacterial families have been widely observed in drinking water, freshwater, and river water ${ }^{65-68}$, and the 16S rRNA gene from these families could be a feasible target biomarker for evaluating UV irradiation dose at full scale. As water treatment plants have their own unique microbiome ${ }^{69}, 16 \mathrm{~S}$ rRNA gene amplicon sequencing to screen for these families, and potentially other biomarker target organisms, could then support targeted gene analysis, e.g., qPCR, to be applied routinely to assess UV disinfection. Longer fragment length of the GPCR target (compared with that used in this sequencing-based study) could increase the resolution of the methodology, as more UV damage can be observed with qPCR of longer amplicons ${ }^{19}$.
The need for molecular biology techniques was supported by observations in this study and others ${ }^{70}$ of HPCs, where log reductions attributed to UV irradiation were lower than previously determined with lab-cultivated organisms ${ }^{1}$. Several taxa that have been identified from drinking water by growth on $\mathrm{HPCs}^{71-73}$ were among the taxa identified by sequencing in this study as UVsensitive, including Methylophilaceae, Sphingobacteriales, and Comamonadaceae correlating with the reduction in HPCs by UV irradiation (Fig. 6); however, no change in HPCs was observed when comparing the UV-irradiated water before and after storage, which was seen by molecular techniques (Fig. 1). Mofidi and Linden ${ }^{74}$ showed regrowth of HPCs following UV disinfection at 200,600 , and $1400 \mathrm{~J} / \mathrm{m}^{2}$, and 7 days of storage at $20^{\circ} \mathrm{C}$ to the same counts as the non-irradiated control, with regrowth attributed to the robustness of the natural bacterial community in drinking water, and likely temperatures, as this was not observed in the current study, where a lower temperature was used for storage. Thus, HPCs are particularly unsuitable for monitoring quality of UV-irradiated water in systems where water temperatures are low, with overall low numbers making logreduction comparison difficult or meaningless. This was also the case for coliforms and $E$. coli, which were completely removed by UV irradiation, as expected ${ }^{4,75}$.

Although UV treatment is widely used in full-scale drinking water treatment plants, it is difficult to apply traditional 


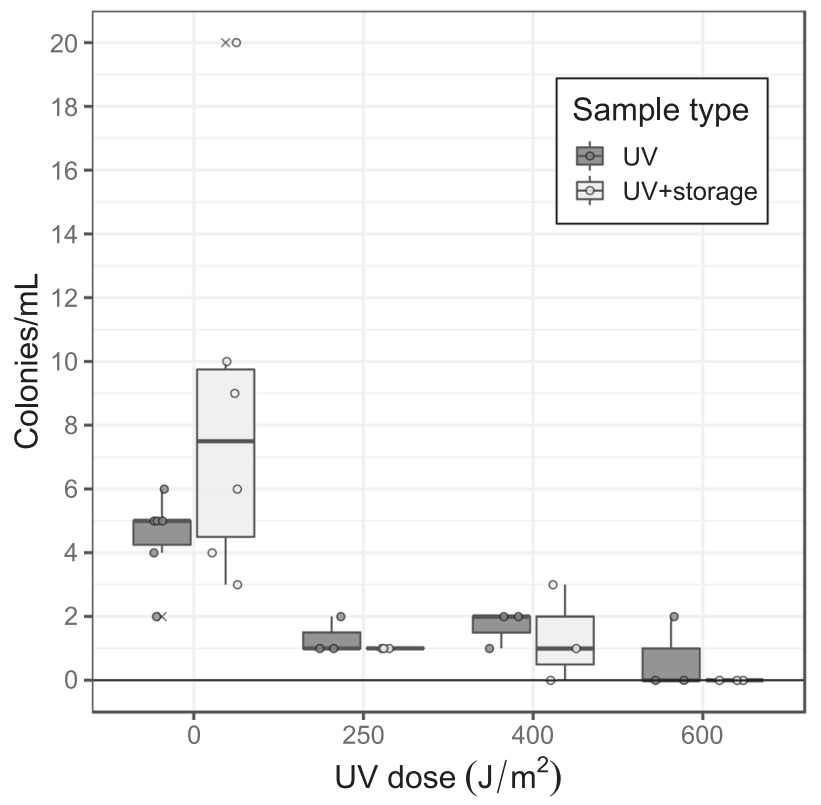

Fig. 6 Heterotrophic plate counts of water exposed to different UV doses, and following storage. Water exposed to different UV doses (dark gray), and following storage for 6 days at $7^{\circ} \mathrm{C}$ (light gray). $n=6$ for UV dose of $0 \mathrm{~J} / \mathrm{m}^{2}$ and $n=6$ for storage not exposed to UV. $n=3$ for all UV doses $>0$ and sample type. The boxes show the interquartile range, the line inside each box represents the median, whiskers show maximum and minimum values, and the crosses show outliers.

microbiological methods to assess dose and quality of the distributed water. A variety of treatment processes produce water containing microorganisms with different UV susceptibility and different wavelengths of UV can be more efficient on certain organisms ${ }^{76}$. In addition to treatment plants, additional applications of UV disinfection include point-of-use and within the pipe network to prevent regrowth of opportunistic pathogens, including UV LED devices ${ }^{57}$. The need to assess the impact of these technologies, both for process monitoring purposes and to investigate the bacterial community that is exposed to consumers through water, could use a molecular biology approach, based on biomarkers for specific taxa. In addition, as the 16S rRNA gene is a fraction of the complete genome in bacteria, shotgun metagenomics examining the genome of UV-irradiated bacteria could investigate the role of GC content on survival, the sensitivity of specific genes involved in biofilm formation, DNA repair, antibiotic resistance, and virulence to understand how UV irradiation affects the microbiota and quality of drinking water. As the DWDS biofilm also interacts with drinking water quality, the impact of UVexposed water on biofilm formation and composition, in lab- or full scale, would also be of interest.

\section{METHODS}

\section{Sampling of water}

Drinking water was sampled at Görvälnverket waterworks in Stockholm, Sweden. The waterworks operated by Norrvatten $A B$ produces $1.6 \mathrm{~m}^{3} / \mathrm{s}$ drinking water from the surface water taken from Lake Mälaren. Water is produced using flocculation with aluminum sulfate, followed by sedimentation, rapid sand filtration, granulated activated carbon, UV irradiation, addition of monochloramine, and $\mathrm{pH}$ adjustment. The UV aggregate is a low-pressure UV (Trojan UV) emitting light at a wavelength of $254 \mathrm{~nm}$ with the USEPA standard ${ }^{8}$, routinely at a UV dose of $400 \mathrm{~J} / \mathrm{m}^{2}$. The aggregate is $1000 \mathrm{~mm}$ in diameter consisting of ten rows of four UV lamps diagonally placed through the pipe. The UV intensities are measured with five light intensity meters evenly distributed throughout the aggregate measuring UV intensity at $200-300 \mathrm{~nm}$. When sampling was conducted, the flow rate through the UV aggregate was $\sim 500 \mathrm{~L} / \mathrm{s}$ and UV transmittance $\sim 84 \%$. Water exposed to three different doses of UV irradiation $(250,400$, and $\left.600 \mathrm{~J} / \mathrm{m}^{2}\right)$ and water that had not been irradiated $\left(0 \mathrm{~J} / \mathrm{m}^{2}\right)$ were sampled both directly after exposure and following storage for 6 days at $7{ }^{\circ} \mathrm{C}$. The conditions for storage were chosen to resemble the water temperature $\left(\sim 1-8^{\circ} \mathrm{C}\right)$ in spring (February-April) and residence time (maximum 14 days) in this distribution system. General water quality data can be found in Supplementary Table 4. Sampling was done in March on two successive days with sampling for $0 \mathrm{~J} / \mathrm{m}^{2}$ ( $n=3$ for all analyses except $n=2$ for DNA analysis) and $250 \mathrm{~J} / \mathrm{m}^{2}(n=3)$ on day 1 and 0,400 , and $600 \mathrm{~J} / \mathrm{m}^{2}(n=3$, for each dose) on day 2. Each sample was collected in $1 \mathrm{~L}$ sterile borosilicate bottles for DNA analysis, $500 \mathrm{~mL}$ sterile borosilicate bottles for HPCs, and $6 \times 10 \mathrm{~L}$ sterile plastic cans for dead-end ultrafiltration and Colilert analysis. For the storage experiment, water was collected in $2 \mathrm{~L}$ sterile borosilicate bottles for DNA and HPC analyses, wrapped in aluminum foil for 6 days at $7{ }^{\circ} \mathrm{C}\left(0 \mathrm{~J} / \mathrm{m}^{2} n=6\right.$ and each UV dose $\left.n=3\right)$. For DNA analysis, $1 \mathrm{~L}$ water samples were filtered onto $0.22 \mu \mathrm{m}$ filters (Merck, Germany) and filters were stored at $-20^{\circ} \mathrm{C}$ until DNA extraction. Dead-end ultrafiltration ${ }^{29}$ was done using $60 \mathrm{~L}$ of water exposed to UV irradiation doses of 0,400 , and $600 \mathrm{~J} / \mathrm{m}^{2}$. Rexeed 25AX filters (Asahi Kasei Corporation, Tokyo, Japan) were pretreated with fetal calf serum (PAA Laboratories, Waltham, MA, USA) to prevent adhesion of microorganisms. After filtration, the concentrate was eluted by back-flushing with $500 \mathrm{~mL}$ elution buffer (phosphate-buffered saline containing $1 \%$ Tween 80 and $0.01 \%$ Antifoam A (both from SigmaAldrich, St. Louis, MO, USA). The final volume typically consisted of $600-700 \mathrm{~mL}$.

\section{Conventional water quality parameters}

HPCS were determined by the SS-EN ISO 6222:1999 standard with the pour plate method using $1 \mathrm{~mL}$ of water and addition of melted yeast peptone agar, followed by incubation at $22^{\circ} \mathrm{C}$ for $3(72 \mathrm{~h})$ and 7 days $(168 \mathrm{~h})$ in triplicate. Concentrations of coliforms and E. coli were assessed using $100 \mathrm{~mL}$ of the dead-end ultrafiltered eluate water with the Colilert ${ }^{\circledR}-18$ (IDEXX Laboratories Sverige $\mathrm{AB}$ ) according to the manufacturer's instructions.

\section{Bacterial community analysis}

DNA was extracted from filter papers using the FastDNA Spin Kit for Soil (MP Biomedicals). Filters were cut into strips and added to Lysing Matrix E tubes with pre-added sodium phosphate, then extracted following the manufacturer's instructions. Empty filters were extracted for use as negative controls. Extracted DNA was stored at $-20^{\circ} \mathrm{C}$. The V3-V4 region of the 16S rRNA gene was amplified using primers $341 \mathrm{~F}\left(5^{\prime}-\right.$ CCTACGGGNGGCWGCAG-3') and 785 R (5'-GACTACHVGGGTATCTAATCC-3' ${ }^{\prime 7}$. The PCR reaction $(25 \mu \mathrm{L})$ contained $12.6 \mu \mathrm{L}$ MilliQ-water, $10 \mu \mathrm{L} 5$ Prime Hot MasterMix (Quantabio, USA), $0.4 \mu \mathrm{L}\left(20 \mathrm{mg} \mathrm{mL}^{-1}\right.$ ) bovine serum albumin, $0.5 \mu \mathrm{L}(10 \mu \mathrm{M})$ forward and reverse primers, and $1 \mu \mathrm{L}$ template DNA. The PCR cycling settings were $94^{\circ} \mathrm{C}$ for 3 min and 35 cycles of $94^{\circ} \mathrm{C}$ for $45 \mathrm{~s}$, $50^{\circ} \mathrm{C}$ for $1 \mathrm{~min}, 72^{\circ} \mathrm{C}$ for $1.5 \mathrm{~min}$, and a final step of $72^{\circ} \mathrm{C}$ for $10 \mathrm{~min}$. Samples were analyzed in triplicate PCR reactions and pooled together. Pooled amplicons were visualized by agarose gel and DNA concentration quantified using a Qubit 2.0 dsDNA BR Assay Kit (Thermo Fisher Scientific, USA). No amplicons were visible on the agarose gel for the negative controls, which were then excluded from further analyses. Fifty nanograms of each pooled amplicon were pooled together, purified using Select-Asize DNA clean and concentrator (Zymo Research, catalog \#4080), and quantified using Qubit. The concentration was adjusted to $2 \mathrm{nM}$ and the library was denatured and diluted according to the manufacturer's instruction (Illumina, USA), with $10 \%$ PhiX added to the sequencing run and sequenced using the MiSeq Reagent Kit v3 (600-cycles) (Illumina), according to the manufacturer's instructions.

\section{Bioinformatics and statistics}

Raw data from sequencing was demultiplexed with deML ${ }^{78}$. Demultiplexed reads were imported and processed in QIIME 2, version 2018.8.0 ${ }^{79}$; forward and reverse reads were truncated using DADA2 ${ }^{80}$ at $250 \mathrm{bp}$, classified using the Greengenes database ${ }^{81}$, and phylogenetic tree created with FastTree $^{82}$. The feature table and phylogenetic tree from QIIME 2 were imported to the Phyloseq package ${ }^{83}$ in $\mathrm{R}^{84}$. Singletons and ASVs at a frequency $<0.005 \%$ of the total number of reads ${ }^{85}$ and ASVs with $<15$ reads in 4 samples were removed. Reads were normalized with the transform_sample_counts function to relative abundances. CCA was done using the vegan package ${ }^{86}$ with the ASV table, UV as a numeric variable, and sample type (after UV exposure or stored for 6 days at $7^{\circ} \mathrm{C}$ ) as a factor, 
the CCA output was followed by an ANOVA permutation test for CCA. Principal Coordinates Analysis plot using Bray-Curtis dissimilarity was done and visualized using Phyloseq and the ggplot2 package ${ }^{87}$, and ADONIS statistics performed using the vegan package. Data were agglomerated at different taxonomic ranks in Phyloseq and wrangled using Tidyverse $R$ package ${ }^{88}$. Linear regression plots were plotted in $\mathrm{R}$ with ggplot $2^{87}$, ggpubr $^{89}$, and ggpmisc ${ }^{90}$ packages, and the linear regression model calculated with the Im function, Pearson's correlation, and correlation coefficient calculated using the cor.test function in R. All other statistical analyses were done using base R. Non-normalized reads were used for differential abundance analysis using DESeq ${ }^{91}$ within Phyloseq $\left(P_{\text {adjusted }}<\right.$ $0.05)$, excluding samples which were stored and accounting for the UV dose as a numeric parameter and visualized in ggplot2. Output ASVs from DESeq2 were visualized in a phylogenetic tree using ggtree ${ }^{92}$. Species diversity indices were calculated with non-normalized reads with the Phyloseq package (Shannon Index and observed ASVs) and custom scripts (Pielou's measure).

Log reductions of HPCs $(\mathrm{H})$ were calculated using Eq. 1:

$H=\log _{10}\left(N_{0}\right)-\log _{10}(N)$

where $N_{0}$ is the HPCs of the non-irradiated water and $N$ the HPCs of the irradiated water at a specific dose. The SDs of log reductions $(\sigma)$ were calculated with Eq. (2):

$\sigma=\sqrt{\left(\frac{\sigma_{N_{0}}^{2}}{n_{0}}+\frac{\sigma_{N}^{2}}{n}\right)}$

using $\log _{10}$ values of HPCs where $\sigma_{N_{0}}$ is the SD of $N_{0}$ and $\sigma_{\mathrm{N}}$ the SD of $N, n_{0}$ is the sample size of the non-irradiated water, and $n$ the sample size of the irradiated water at a specific dose.

\section{DATA AVAILABILITY}

DNA sequences are available at the NCBI Sequence Read Archive, accession number: PRJNA579449.

Received: 12 November 2019; Accepted: 21 February 2020; Published online: 19 March 2020

\section{REFERENCES}

1. Hijnen, W. A. M., Beerendonk, E. F. \& Medema, G. J. Inactivation credit of UV radiation for viruses, bacteria and protozoan (oo)cysts in water: a review. Water Res. 40, 3-22 (2006).

2. Reckhow, D. A., Linden, K. G., Kim, J., Shemer, H. \& Makdissy, G. Effect of UV treatment on DBP formation. J. Am. Water Works Assoc. 102, 100-113 (2010).

3. Hayes, S. L., Sivaganesan, M., White, K. M. \& Pfaller, S. L. Assessing the effectiveness of low-pressure ultraviolet light for inactivating Mycobacterium avium complex (MAC) micro-organisms. Lett. Appl. Microbiol. 47, 386-392 (2008).

4. Sommer, R., Lhotsky, M., Haider, T. \& Cabaj, A. UV inactivation, liquid-holding recovery, and photoreactivation of Escherichia coli 0157 and other pathogenic Escherichia coli strains in water. J. Food Protect. 63, 1015-1020 (2000).

5. Christensen, J. \& Linden, K. G. How particles affect UV light in the UV disinfection of unfiltered drinking water. J. Am. Water Works Assoc. 95, 179-189 (2003).

6. Farrell, C. et al. Turbidity composition and the relationship with microbial attachment and UV inactivation efficacy. Sci. Total Environ. 624, 638-647 (2018).

7. Jungfer, C., Schwartz, T. \& Obst, U. UV-induced dark repair mechanisms in bacteria associated with drinking water. Water Res. 41, 188-196 (2007).

8. USEPA. Ultraviolet Disinfection Guidance Manual for the Final Long Term 2 Enhanced Surface Water Treatment Rule. 815-R-06-007 (Environmental Protection Agency, 2006).

9. Sinha, R. P. \& Häder, D. P. UV-induced DNA damage and repair: A review. Photochem. Photobiol. Sci. 1, 225-236 (2002).

10. Rastogi, R. P., Richa, Kumar, A., Tyagi, M. B. \& Sinha, R. P. Molecular mechanisms of ultraviolet radiation-induced DNA damage and repair. J. Nucleic Acids 2010, 592980 (2010).

11. Ravanat, J.-L., Douki, T. \& Cadet, J. Direct and indirect effects of UV radiation on DNA and its components. J. Photochem. Photobiol. B Biol. 63, 88-102 (2001).

12. Jungfer, C., Schwartz, T. \& Obst, U. UV-induced dark repair mechanisms in bacteria associated with drinking water. Water Res. https://doi.org/10.1016/j. watres.2006.09.001 (2007).

13. Wellinger, R. \& Thoma, F. Taq DNA polymerase blockage at pyrimidine dimers. Nucleic Acids Res. 24, 1578-1579 (1996).
14. Harm, W. Effects of dose fractionation on ultraviolet survival of Escherichia coli. Photochem. Photobiol. 7, 73-86 (1968).

15. Leuker, G. Description and application of biodosimetry - a testing procedure for UV systems. J. Water Supply. Res. Technol. Aqua 48, 154-160 (1999).

16. Van Nevel, S. et al. Flow cytometric bacterial cell counts challenge conventional heterotrophic plate counts for routine microbiological drinking water monitoring. Water Res. https://doi.org/10.1016/j.watres.2017.01.065 (2017).

17. Ben Said, M., Masahiro, O. \& Hassen, A. Detection of viable but non cultivable Escherichia coli after UV irradiation using a lytic Q $\beta$ phage. Ann. Microbiol. 60, 121-127 (2010).

18. Guo, L. et al. Population and single cell metabolic activity of UV-induced VBNC bacteria determined by CTC-FCM and D2O-labeled Raman spectroscopy. Environ. Int. 130, 104883 (2019).

19. Süß. J., Volz, S., Obst, U. \& Schwartz, T. Application of a molecular biology concept for the detection of DNA damage and repair during UV disinfection. Water Res. 43, 3705-3716 (2009).

20. McKinney, C. W. \& Pruden, A. Ultraviolet disinfection of antibiotic resistant bacteria and their antibiotic resistance genes in water and wastewater. Environ. Sci. Technol. 46, 13393-13400 (2012).

21. Nocker, A. et al. Assessment of UV-C-induced water disinfection by differential PCR-based quantification of bacterial DNA damage. J. Microbiol. Methods 149, 89-95 (2018)

22. Kauser, I., Ciesielski, M. \& Poretsky, R. S. Ultraviolet disinfection impacts the microbial community composition and function of treated wastewater effluent and the receiving urban river. PeerJ 7, e7455 (2019).

23. Beck, S. E. et al. Wavelength dependent UV inactivation and DNA damage of adenovirus as measured by cell culture infectivity and long range quantitative PCR. Environ. Sci. Technol. 48, 591-598 (2014).

24. Nizri, L. et al. Development of a molecular method for testing the effectiveness of UV systems on-site. Water Res. 127, 162-171 (2017).

25. Zaitlin, B. \& Watson, S. B. Actinomycetes in relation to taste and odour in drinking water: myths, tenets and truths. Water Res. 40, 1741-1753 (2006).

26. Kip, N. \& van Veen, J. A. The dual role of microbes in corrosion. ISME J. 9, 542-551 (2015).

27. Pinto, A. J., Xi, C. \& Raskin, L. Bacterial community structure in the drinking water microbiome is governed by filtration processes. Environ. Sci. Technol. 46, 8851-8859 (2012).

28. Laroche, O. et al. Understanding bacterial communities for informed biosecurity and improved larval survival in Pacific oysters. Aquaculture 497, 164-173 (2018).

29. Smith, C. M. \& Hill, V. R. Dead-end hollow-fiber ultrafiltration for recovery of diverse microbes from water. Appl. Environ. Microbiol. 75, 5284-5289 (2009).

30. Warnecke, F., Sommaruga, R., Sekar, R., Hofer, J. S. \& Pernthaler, J. Abundances, identity, and growth state of actinobacteria in mountain lakes of different UV transparency. Appl. Environ. Microbiol. 71, 5551-5559 (2005).

31. Douki, T. \& Cadet, J. Individual determination of the yield of the main UV-induced dimeric pyrimidine photoproducts in DNA suggests a high mutagenicity of CC photolesions. Biochemistry https://doi.org/10.1021/bi0022543 (2001).

32. Reichenberger, E. R., Rosen, G., Hershberg, U. \& Hershberg, R. Prokaryotic nucleotide composition is shaped by both phylogeny and the environment. Genome Biol. Evol. 7, 1380-1389 (2015).

33. Arrage, A. A., Phelps, T. J., Benoit, R. E. \& White, D. C. Survival of subsurface microorganisms exposed to UV radiation and hydrogen peroxide. Appl. Environ. Microbiol. 59, 3545-3550 (1993).

34. Rasuk, M. C. et al. UV-resistant Actinobacteria from high-altitude Andean Lakes: isolation, characterization and antagonistic activities. Photochem. Photobiol. 93, 865-880 (2017)

35. Barka, E. A. et al. Taxonomy, physiology, and natural products of Actinobacteria. Microbiol. Mol. Biol. Rev. 80, 1-43 (2016).

36. Mason, J. M. \& Setlow, P. Essential role of small, acid-soluble spore proteins in resistance of Bacillus subtilis spores to UV light. J. Bacteriol. 167, 174-178 (1986).

37. Riesenman, P. J. \& Nicholson, W. L. Role of the spore coat layers in Bacillus subtilis spore resistance to hydrogen peroxide, artificial UV-C, UV-B, and solar UV radiation. Appl. Environ. Microbiol. 66, 620-626 (2000).

38. Krieg, N. R., et al. (eds) Bergey's Manual ${ }^{\circledast}$ of Systematic Bacteriology (Springer, New York, NY, 2010). https://doi.org/10.1007/978-0-387-68572-4 3.

39. Ordoñez, O. F., Flores, M. R., Dib, J. R., Paz, A. \& Farías, M. E. Extremophile culture collection from Andean Lakes: extreme pristine environments that host a wide diversity of microorganisms with tolerance to UV radiation. Microb. Ecol. 58, 461-473 (2009).

40. Gupta, R. S. The phylogeny of proteobacteria: relationships to other eubacterial phyla and eukaryotes. FEMS Microbiol. Rev. https://doi.org/10.1111/j.15746976.2000.tb00547.x (2014).

41. Gupta, R. S. \& Mok, A. Phylogenomics and signature proteins for the alpha Proteobacteria and its main groups. BMC Microbiol. 7, 106 (2007). 
42. Salcher, M. M., Schaefle, D., Kaspar, M., Neuenschwander, S. M. \& Ghai, R. Evolution in action: habitat transition from sediment to the pelagial leads to genome streamlining in Methylophilaceae. ISME J. https://doi.org/10.1038/s41396-0190471-3 (2019).

43. Guarischi-Sousa, R. et al. Complete genome sequence of the potato pathogen Ralstonia solanacearum UY031. Stand. Genomic Sci. 11, 7 (2016).

44. Jara, E. et al. The complex pattern of codon usage evolution in the family Comamonadaceae. Ecol. Genet. Genomics 6, 1-8 (2018).

45. Hahn, M. W., Jezberová, J., Koll, U., Saueressig-Beck, T. \& Schmidt, J. Complete ecological isolation and cryptic diversity in Polynucleobacter bacteria not resolved by $16 \mathrm{~S}$ rRNA gene sequences. ISME J. 10, 1642-1655 (2016).

46. Oguma, K. et al. Determination of pyrimidine dimers in Escherichia coli and Cryptosporidium parvum during UV light inactivation, photoreactivation, and dark repair. Appl. Environ. Microbiol. 67, 4630-4637 (2001).

47. Liu, J. et al. Occurrence and fate of ultramicrobacteria in a full-scale drinking water treatment plant. Front. Microbiol. 9, 2922 (2018).

48. Ortmann, A. C. \& Santos, T. T. L. Spatial and temporal patterns in the Pelagibacteraceae across an estuarine gradient. FEMS Microbiol. Ecol. 92, 133 (2016).

49. Morris, R. M. et al. SAR11 clade dominates ocean surface bacterioplankton communities. Nature 420, 806-810 (2002).

50. Giovannoni, S. J. et al. Genetics: genome streamlining in a cosmopolitan oceanic bacterium. Science 309, 1242-1245 (2005).

51. Malmstrom, R. R., Cottrell, M. T., Elifantz, H. \& Kirchman, D. L. Biomass production and assimilation of dissolved organic matter by SAR11 bacteria in the Northwest Atlantic Ocean. App. Environ. Microbiol. 71, 2979-2986 (2005).

52. Moss, T., Dimitrov, S. I. \& Houde, D. UV-laser crosslinking of proteins to DNA. Methods 11, 225-234 (1997).

53. Du, K., Liu, J., Zhou, B. \& Yuan, R. Isolation of bacteria capable of removing 2methylisoborneol and effect of cometabolism carbon on biodegradation. Environ. Eng. Res. 21, 256-264 (2016).

54. Wingender, J. Biofilms in drinking water and their role as reservoir for pathogens. Int. J. Hyg. Environ. Health 214, 417-423 (2011).

55. Shin, G.-A., Lee, J.-K., Freeman, R. \& Cangelosi, G. A. Inactivation of Mycobacterium avium complex by UV irradiation. Appl. Environ. Microbiol. 74, 7067-7069 (2008)

56. Taylor, R. H., Falkinham lii, J. O., Norton, C. D. \& Lechevallier, M. W. Chlorine, chloramine, chlorine dioxide, and ozone susceptibility of Mycobacterium avium. Appl. Environ. Microbiol. 66, 1702-1705 (2000).

57. Linden, K. G., Hull, N. \& Speight, V. Thinking outside the treatment plant: UV for water distribution system disinfection. Acc. Chem. Res. https://doi.org/10.1021/ acs.accounts.9b00060 (2019).

58. Henne, K., Kahlisch, L., Brettar, I. \& Höfle, M. G. Analysis of structure and composition of bacterial core communities in mature drinking water biofilms and bulk water of a citywide network in Germany. Appl. Environ. Microbiol. https://doi. org/10.1128/AEM.06373-11 (2012)

59. Liu, G., et al. Pyrosequencing reveals bacterial communities in unchlorinated drinking water distribution system: an integral study of bulk water, suspended solids, loose deposits, and pipe wall biofilm. Environ. Sci. Technol. https://doi.org/ 10.1021/es5009467 (2014).

60. Regan, J. M., Harrington, G. W., Baribeau, H., Leon, R. D. \& Noguera, D. R. Diversity of nitrifying bacteria in full-scale chloraminated distribution systems. Water Res. 37, 197-205 (2003)

61. Lipponen, M. T. T. et al. Occurrence of nitrifiers and diversity of ammoniaoxidizing bacteria in developing drinking water biofilms. Water Res. 38, 4424-4434 (2004).

62. Ling, F., Hwang, C., LeChevallier, M. W., Andersen, G. L. \& Liu, W.-T. Core-satellite populations and seasonality of water meter biofilms in a metropolitan drinking water distribution system. ISME J. 10, 582-595 (2016).

63. Navarro-Noya, Y. E. et al. Pyrosequencing analysis of the bacterial community in drinking water wells. Microb. Ecol. 66, 19-29 (2013).

64. Bohrerova, Z., Bohrer, G., Mohanraj, S. M., Ducoste, J. \& Linden, K. G. Experimental measurements of fluence distribution in a UV reactor using fluorescent microspheres. Environ. Sci. Technol. 39, 8925-8930 (2005).

65. Qin, K., Struewing, I., Domingo, J. S., Lytle, D. \& Lu, J. Opportunistic pathogens and microbial communities and their associations with sediment physical parameters in drinking water storage tank sediments. Pathogens 6, pii: E54 (2017).

66. Zeng, D. N. et al. Analysis of the bacterial communities associated with different drinking water treatment processes. World J. Microbiol. Biotechnol. 29, 1573-1584 (2013).

67. Zaremba-Niedzwiedzka, K. et al. Single-cell genomics reveal low recombination frequencies in freshwater bacteria of the SAR11 clade. Genome Biol. 14, R130 (2013).

68. Henson, M. W. et al. Nutrient dynamics and stream order influence microbial community patterns along a 2914 kilometer transect of the Mississippi River. Limnol. Oceanogr. 63, 1837-1855 (2018).
69. Proctor, C. R. \& Hammes, F. Drinking water microbiology-from measurement to management. Curr. Opin. Biotechnol. 33, 87-94 (2015).

70. Lehtola, M. J. et al. Impact of UV disinfection on microbially available phosphorus, organic carbon, and microbial growth in drinking water. Water Res. 37, 1064-1070 (2003).

71. Tokajian, S. T., Hashwa, F. A., Hancock, I. C. \& Zalloua, P. A. Phylogenetic assessment of heterotrophic bacteria from a water distribution system using $16 \mathrm{~S}$ rDNA sequencing. Can. J. Microbiol. 51, 325-335 (2005).

72. Ultee, A., Souvatzi, N., Maniadi, K. \& König, H. Identification of the culturable and nonculturable bacterial population in ground water of a municipal water supply in Germany. J. Appl. Microbiol. 96, 560-568 (2004).

73. Tokajian, S. \& Hashwa, F. Microbiological quality and genotypic speciation of heterotrophic bacteria isolated from potable water stored in household tanks. Water Qual. Res. J. Can. 39, 64-73 (2004).

74. Mofidi, A. A. \& Linden, K. G. Disinfection effectiveness of ultraviolet (UV) light for heterotrophic bacteria leaving biologically active filters. J. Water Supply. Res. Technol. Aqua. 53, 553-566 (2004).

75. Butler, R. C., Lund, V. \& Carlson, D. A. Susceptibility of Campylobacter jejuni and Yersinia enterocolitica to UV Radiation. Appl. Environ. Microbiol. 53, 375-378 (1987).

76. Rattanakul, S. \& Oguma, K. Inactivation kinetics and efficiencies of UV-LEDs against Pseudomonas aeruginosa, Legionella pneumophila, and surrogate microorganisms. Water Res. https://doi.org/10.1016/j.watres.2017.11.047 (2018).

77. Klindworth, A. et al. Evaluation of general $16 \mathrm{~S}$ ribosomal RNA gene PCR primers for classical and next-generation sequencing-based diversity studies. Nucleic Acids Res. 41, e1 (2013).

78. Renaud, G., Stenzel, U., Maricic, T., Wiebe, V. \& Kelso, J. deML: robust demultiplexing of Illumina sequences using a likelihood-based approach. Bioinformatics 31, 770-772 (2015)

79. Bolyen, E. et al. Reproducible, interactive, scalable and extensible microbiome data science using QIIME 2. Nat. Biotechnol. 37, 852-857 (2019).

80. Callahan, B. J. et al. DADA2: high-resolution sample inference from Illumina amplicon data. Nat. Methods 13, 581-583 (2016).

81. Desantis, T. Z. et al. Greengenes, a chimera-checked 165 rRNA gene database and workbench compatible with ARB. Appl. Environ. Microbiol. 72, 5069-5072 (2006).

82. Price, M. N., Dehal, P. S. \& Arkin, A. P. Fasttree: computing large minimum evolution trees with profiles instead of a distance matrix. Mol. Biol. Evolution 26, 1641-1650 (2009).

83. McMurdie, P. J. \& Holmes, S. phyloseq: an R package for reproducible interactive analysis and graphics of microbiome census data. PLoS ONE 8, e61217 (2013).

84. R Core Team. R: A Language and Environment for Statistical Computing (R Foundation for Statistical Computing, 2018).

85. Bokulich, N. A. et al. Quality-filtering vastly improves diversity estimates from Illumina amplicon sequencing. Nat. Methods 10, 57-59 (2013).

86. Oksanen, J. et al. vegan: Community Ecology Package. R. Package Version 2.5-4 (2019)

87. Wickham, H. ggplot2: Elegant Graphics for Data Analysis (Springer-Verlag, New York, 2016)

88. Wickham, H. tidyverse: Easily Install and Load the 'Tidyverse'. R package version 1.2.1. Available at: https://cran.r-project.org/package=tidyverse (2017).

89. Kassambara, A. ggpubr: 'ggplot2' Based Publication Ready Plots (2018).

90. Aphalo, P. J. Learn R... as you learnt your mother tongue. (Leanpub, 2016).

91. Love, M. I., Huber, W. \& Anders, S. Moderated estimation of fold change and dispersion for RNA-seq data with DESeq2. Genome Biol. 15, 550 (2014).

92. Yu, G., Smith, D. K., Zhu, H., Guan, Y. \& Lam, T. T.-Y. ggtree: an r package for visualization and annotation of phylogenetic trees with their covariates and other associated data. Methods Ecol. Evol. 8, 28-36 (2017).

\section{ACKNOWLEDGEMENTS}

We thank the employees at Norrvatten $A B$ for contributions in planning the experiments at full scale with a special thanks to Jamileh Mirzai and lab colleagues for assistance in the lab. This study was funded by Sweden Water Research AB, DRICKS center for drinking water research, Swedish Water and Wastewater Association (SVU), Swedish Civil Contingencies Agency (MSB), and Norrvatten AB. Open access funding provided by Lund University.

\section{AUTHOR CONTRIBUTIONS}

K.P., L.H., R.D., M.F., C.J.P., and P.R. planned the experiments. K.P., L.H., and R.D. conducted the sampling. K.P., K.J., R.D., and E.S. did the experimental work. K.P., J.A., and C.Ö. performed data analysis. K.P., C.J.P., and P.R. drafted the manuscript. All authors contributed to the final manuscript. 


\section{COMPETING INTERESTS}

The authors declare no competing interests.

\section{ADDITIONAL INFORMATION}

Supplementary information is available for this paper at https://doi.org/10.1038/ s41545-020-0057-7.

Correspondence and requests for materials should be addressed to C.J.P.

Reprints and permission information is available at http://www.nature.com/ reprints

Publisher's note Springer Nature remains neutral with regard to jurisdictional claims in published maps and institutional affiliations.
Open Access This article is licensed under a Creative Commons International License, which permits use, sharing, adaptation, distribution and reproduction in any medium or format, as long as you give appropriate credit to the original author(s) and the source, provide a link to the Creative Commons license, and indicate if changes were made. The images or other third party material in this article are included in the article's Creative Commons license, unless indicated otherwise in a credit line to the material. If material is not included in the article's Creative Commons license and your intended use is not permitted by statutory regulation or exceeds the permitted use, you will need to obtain permission directly from the copyright holder. To view a copy of this license, visit http://creativecommons. org/licenses/by/4.0/.

(c) The Author(s) 2020 